\title{
O USO DE CLORETO DE CÁlCIO E DA CAL PARA O TRATAMENTO PÓS-COLHEITA DE PODRIDÕES EM MAÇÃ ${ }^{1}$
}

\author{
AURI BRACKMANN², MARCELO CERETTA³ ${ }^{3}$ MÁRCIA VIZZOTTO ${ }^{4}$
}

\begin{abstract}
RESUMO - Foi desenvolvido um experimento para avaliar a influência da contaminação da água e a eficiência de produtos químicos na lavagem de maçãs cvs. Gala e Fuji sobre a ocorrência de podridão em frutos com ferimentos. O delineamento experimental foi inteiramente casualizado, com quatro repetições por cultivar e unidade experimental composta por 25 frutos. Os tratamentos foram: a) Testemunha (seca); b) Testemunha em água; c) Inoculação com água com esporos; d) Inoculação em água com esporos +30 horas em temperatura ambiente; e) 30 horas em temperatura ambiente + inoculação em água com esporos; f) $\left.\mathrm{Cal} \mathrm{Ca(OH})_{2}(1,5 \%) ; \mathrm{g}\right) \mathrm{CaCl}_{2}(1,5 \%)$. Inicialmente, todos os frutos sofreram quatro lesões de $0,2 \mathrm{~cm}$ de diâmetro por $0,5 \mathrm{~cm}$ de profundidade na região equatorial. Os frutos foram inoculados com uma solução de esporos de Penicillium sp. Após aplicação dos respectivos tratamentos, os frutos foram armazenados sob refrigeração a $0^{\circ} \mathrm{C}$ para a 'Gala' e $-0,5^{\circ} \mathrm{C}$ para a 'Fuji'. As avaliações de incidência de podridão foram realizadas na abertura das câmaras (60 dias) e após 7 e 14 dias de exposição a $20^{\circ} \mathrm{C}$. Não houve ocorrência de podridão aos 60 dias para os frutos tratados com cal, não diferindo estatisticamente dos tratados com $\mathrm{CaCl}_{2}$. Aos sete e 14 dias, a cal mostrou-se mais eficiente que o $\mathrm{CaCl}_{2}$ na cv. Gala. Os frutos que ficaram 30 horas em temperatura ambiente antes de serem inoculados com uma solução de esporos, apresentaram menor incidência de podridão que os inoculados antes da exposição por 30 horas à temperatura ambiente, indicando que, após a inoculação, o fungo necessita de temperatura adequada para causar podridão.
\end{abstract}

Termos para indexação: Malus domestica, armazenamento, Penicillim sp.

\section{USE OF CALCIUM CLORIDE AND LIME TO CONTROL POSTHARVEST ROT IN APPLES}

\begin{abstract}
The experiment was carried out with the objective to evaluate the influence of the presence of Penicillium $s p$ spores in washing water and rot control with chemical products added to the water during postharvest cleaning of 'Gala' and 'Fuji' apples. The experimental design was entirely randomized, with 4 replications of 25 fruits. The treatments were: a) control (dry), b) clean water, c) dipping in water with spores, d) dipping in water with spores +30 hours exposure of fruits to $20^{\circ} \mathrm{C}$, e) 30 hours at $20^{\circ} \mathrm{C}+$ dipping in water with spores, f) $\left.\mathrm{Ca}(\mathrm{OH})_{2}(1,5 \%), \mathrm{g}\right) \mathrm{CaCl}_{2}(1,5 \%)$. Prior to the treatment application, fruits were injured. All fruits had four injuries of $0.2 \mathrm{~cm}$ diameter and $0.5 \mathrm{~cm}$ depth in the equatorial region. The fruits were dipped in solution with Penicillium $s p$ spores. After treatment, fruits were cold stored at $0^{\circ} \mathrm{C}$ for 'Gala' and $-0,5^{\circ} \mathrm{C}$ for 'Fuji'. Rot incidence was evaluated at chamber opening (60 days) and after 7 and 14 days of shelf life at $20^{\circ} \mathrm{C}$. After 60 days storage there wasn't rot incidence on fruits treated with $\mathrm{Ca}(\mathrm{OH})_{2}$ and $\mathrm{CaCl}_{2}$. During the shelflife the $\mathrm{Ca}(\mathrm{OH})_{2}$ was more efficient than $\mathrm{CaCl}_{2}$ in cv. Gala. Fruits maintained at $20^{\circ} \mathrm{C}$ during 30 hours before inoculation with spore solution, showed less rot incidence that fruits inoculated immediately after injuring. Fruits dipped in clean water had lower rot incidence that fruits dipped in spore solution.
\end{abstract}

Index terms: Malus domestica, storage, Penicillium sp.

\section{INTRODUÇÃO}

Após a colheita, podem ocorrer elevadas perdas de frutos, causadas por podridões associadas a fungos, como Penicillium expansum, Alternaria alternata, Botrytis cinerea, Rhizopus sp, entre outros. O Penicillium expansum, principal causador de podridões em maçãs, infecta os frutos através de ferimentos (Sanhueza, 1996). No beneficiamento de maçãs, o tratamento da água de lavagem na linha de seleção, visando a diminuir o inóculo de patógenos, é fator importante a ser considerado no controle de podridões. Muitas vezes, a deficiente renovação da água ou solução fungicida na linha de seleção e classificação pode ocasionar um aumento do inóculo, contribuindo para a ocorrência de infecções nos frutos que apresentarem ferimentos, ao invés de controlar os fungos nela presentes. Alguns produtos são utilizados na lavagem dos frutos, como hipoclorito de sódio e digluconato de clorohexidina. O primeiro tem o incoveniente de apresentar efeito corrosivo ao maquinário, e o segundo, de ser um produto tóxico ao homem. Também são usados tratamentos com fungicidas, como o Iprodione e o Imazalil, que são igualmente nocivos ao homem. Mas o uso de substâncias químicas sintéticas para o controle de

1 Trabalho $n^{\circ}$ 210/2000. Recebido: 19/09/2000. Aceito para publicação: 17/03/2001.

2 Engenheiro Agrônomo, Doutor, Professor do Departamento de Fitotecnia da Universidade Federal de Santa Maria (UFSM). 97105-900, Santa Maria, RS. Autor para correspondência.

3 Engenheiro Agrônomo, M.Sc., aluno do Programa de Pós-graduação em Agronomia, area de concentração Fruticultura de Clima Temperado da Universidade Federal de Pelotas (UFPel). Bolsista do CNPq.

4 Engenheiro Agrônomo, aluna do Programa de Pós-graduação em Agronomia, área de concentração Fruticultura de Clima Temperado, da UFPel. Bolsista do CNPq. 
doenças, especialmente em tratamentos pós-colheita, está tornando-se cada vez mais restrito. No entanto, existem produtos alternativos para o controle de podridões cuja eficiência não é muito conhecida, como cal $\left(\mathrm{Ca}(\mathrm{OH})_{2}\right)$ e cloreto de cálcio $\left(\mathrm{CaCl}_{2}\right)$. A imersão dos frutos em solução de cloreto de cálcio reduz a incidência de podridões (Zaffari et al., 1989; Brackmann et al., 1996), além de contribuir na redução do "bitter pit" e outros distúrbios fisiológicos (Paladini \& Ebert, 1987).

Em alguns frutos, como o kiwi, e tubérculos, como a batata-doce, a exposição à temperatura ambiente após a colheita, chamada de cura, é uma prática que permite a cicatrização das lesões e diminui a ocorrência de podridões (Wang, 1994; Pinilla et al., 1994).

Portanto, o objetivo deste trabalho foi de avaliar o efeito do uso em pós-colheita de $\mathrm{CaCl}_{2}$ e $\mathrm{Ca}(\mathrm{OH})_{2}$ na ocorrência de podridões em maçãs cultivares Gala e Fuji, submetidas a ferimentos.

\section{MATERIAL E MÉTODOS}

O experimento foi conduzido no Núcleo de Pesquisa em Pós-colheita (NPP) da Universidade Federal de Santa Maria. Utilizaram-se frutos da cultivar Gala e Fuji provenientes de pomar comercial, localizado em Vacaria-RS. O experimento foi constituído de sete tratamentos, com quatro repetições de 25 frutos para cada cultivar, utilizando-se de delineamento experimental inteiramente casualizado.

Os tratamentos avaliados foram: a) Testemunha (seca); b) Imersão em água limpa; c) Inoculação em água com esporos; d) Inoculação em água com esporos +30 horas em temperatura ambiente; e) 30 horas em temperatura ambiente + inoculação em água com esporos; f) Imersão em solução de $\mathrm{Ca}(\mathrm{OH})_{2}(1,5 \%)$; g) Imersão em solução de $\mathrm{CaCl}_{2}$ (1,5\%). Inicialmente, todos os frutos sofreram quatro lesões na região equatorial, com um perfurador de ferro, com ponteira de $2 \mathrm{~mm}$ de diâmetro e $5 \mathrm{~mm}$ de comprimento, para possibilitar a ocorrência de podridão. Os frutos foram inoculados com uma solução de esporos de Penicillium sp. cuja concentração não foi determinada. $\mathrm{O}$ tempo de imersão dos frutos foi de um minuto. Posteriormente, os frutos foram armazenados por 60 dias a $0^{\circ} \mathrm{C}$ para a 'Gala' e $-0,5^{\circ} \mathrm{C}$ para a 'Fuji', com umidade relativa em torno de $92 \%$.

A ocorrência de podridão foi avaliada aos 60 dias de armazenamento (abertura das câmaras), e novamente após 7 e 14 dias de exposição dos frutos a $20^{\circ} \mathrm{C}$, nos quatro ferimentos efetuados em cada fruto. A incidência de podridão nas lesões foi avaliada através do percentual de frutos com podridão e índice de podridão. No primeiro caso, foi considerado fruto podre aquele que apresentava pelo menos uma lesão com incidência de podridão. $\mathrm{O}$ segundo foi determinado pela contagem do número de lesões com incidência de podridões, em que o índice zero significa fruto com lesão sem podridão, e o índice quatro corresponde às quatro lesões com podridão.

Os resultados observados foram submetidos à análise de variância e as médias foram comparadas pelo teste de Tuckey, em nível de $5 \%$ de probabilidade.

\section{RESULTADOS E DISCUSSÃO}

Na análise efetuada na abertura das câmaras (Tabelas 1 e 2), verificou-se que os frutos tratados com cal não apresentaram nenhum ferimento com podridão, em ambas as cultivares. Entretanto, estatisticamente, este tratamento não apresenta diferença com frutos imersos em $\mathrm{H}_{2} \mathrm{O}$ e os tratados com $\mathrm{CaCl}_{2}$. Aos sete dias de exposição a $20^{\circ} \mathrm{C}, \mathrm{o}$ tratamento com cal continua evidenciando-se entre os demais, por apresentar menor percentual de frutos e índice de incidência de podridão. $\mathrm{Na} \mathrm{cv}$. Gala, a cal apresentou eficiência superior ao $\mathrm{CaCl}_{2}$. Este, no entanto, se camparado com a testemunha em água, foi eficiente no controle de podridões na cultivar Fuji. Resultado semelhante foi obtido por Brackmann et al., 1996, que verificaram que o $\mathrm{CaCl}_{2}$ a $2 \%$ reduziu em 44,6 e $47,8 \%$ a ocorrência de podridões para as cultivares Golden Delicious e Fuji, respectivamente, em relação a frutos não tratados. Segundo Bleicher \& Bernardi (1985), o cloreto de cálcio tem efeito fungicida no controle de podridões,

TABELA 1 - Ocorrência de podridões em maçã ‘Gala' após 60 dias de armazenamento a $0^{\circ} \mathrm{C}$ e mais 7 e 14 dias de exposição a $20^{\circ} \mathrm{C}$. Santa Maria, 2000

\begin{tabular}{|c|c|c|c|c|c|c|}
\hline \multirow[t]{2}{*}{ Tratamentos } & \multicolumn{3}{|c|}{ Podridão (\%) } & \multicolumn{3}{|c|}{ Índice de podridão $(0-4)$} \\
\hline & $0 * *$ & 7 & 14 & 0 & 7 & 14 \\
\hline Testemunha (seca) & $4 \mathrm{c}^{*}$ & $19 \mathrm{~d}$ & $29 \mathrm{c}$ & $0,04 \mathrm{~b}$ & $0,22 \mathrm{c}$ & $0,52 \mathrm{~d}$ \\
\hline Água limpa & $2 \mathrm{c}$ & $52 \mathrm{c}$ & $67,7 \mathrm{~b}$ & $0,04 \mathrm{~b}$ & $0,83 \mathrm{c}$ & $1,37 \mathrm{c}$ \\
\hline Água com inóculo & $100 \mathrm{a}$ & $100 \mathrm{a}$ & $100 \mathrm{a}$ & $3,88 \mathrm{a}$ & $4 \mathrm{a}$ & $4 \mathrm{a}$ \\
\hline Água com esporos $+30 \mathrm{~h}$ temp. amb. & $100 \mathrm{a}$ & $100 \mathrm{a}$ & $100 \mathrm{a}$ & $3,98 \mathrm{a}$ & $4 \mathrm{a}$ & $4 \mathrm{a}$ \\
\hline $30 \mathrm{~h}$ temp. amb. + água com esporos & $28 \mathrm{~b}$ & $80 \mathrm{~b}$ & $97 \mathrm{a}$ & $0,34 \mathrm{~b}$ & $1,79 \mathrm{~b}$ & $2,79 \mathrm{~b}$ \\
\hline $\mathrm{Ca}(\mathrm{OH})_{2} 1,5 \%$ & $0 \mathrm{c}$ & $16 \mathrm{~d}$ & $35,1 \mathrm{c}$ & $0,00 \mathrm{~b}$ & $0,26 \mathrm{c}$ & $0,57 \mathrm{~b}$ \\
\hline $\mathrm{CaCl}_{2} 1,5 \%$ & $2,7 \mathrm{c}$ & $57,8 \mathrm{bc}$ & $80,7 \mathrm{~b}$ & $0,07 \mathrm{~b}$ & $0,81 \mathrm{c}$ & $1,78 \mathrm{c}$ \\
\hline CV. (\%) & & 17,33 & & & 15.3 & \\
\hline
\end{tabular}

*Tratamentos não seguidos pela mesma letra, na vertical, diferem pelo teste de Tuckey, em nível de 5\%.

** Dias após abertura das câmaras. 
TABELA 2 - Ocorrência de podridões em maçãs ‘Fuji’ após 60 dias de armazenamento a -0,5 $5^{\circ} \mathrm{C}$ e mais 7 e 14 dias de exposição a $20^{\circ} \mathrm{C}$. Santa Maria, RS, 2000

\begin{tabular}{|c|c|c|c|c|c|c|}
\hline \multirow[t]{2}{*}{ Tratamentos } & \multicolumn{3}{|c|}{ Podridão (\%) } & \multicolumn{3}{|c|}{ Índice de podridão $(0-4)$} \\
\hline & $0 * *$ & 7 & 14 & 0 & 7 & 14 \\
\hline Testemunha (seca) & $1 \mathrm{~d}^{*}$ & $28,2 \mathrm{c}$ & $33,4 \mathrm{c}$ & $0,01 \mathrm{c}$ & $0,39 \mathrm{c}$ & $0,51 \mathrm{c}$ \\
\hline Água limpa & $10 \mathrm{c}$ & $56,7 \mathrm{~b}$ & $70,3 \mathrm{~b}$ & $0,13 \mathrm{c}$ & $0,94 \mathrm{c}$ & $1,46 \mathrm{c}$ \\
\hline Água com inóculo & $100 \mathrm{a}$ & $100 \mathrm{a}$ & $100 \mathrm{a}$ & $4,00 \mathrm{a}$ & $4,00 \mathrm{a}$ & $4,00 \mathrm{a}$ \\
\hline Água com esporos $+30 \mathrm{~h}$ temp. amb. & $100 \mathrm{a}$ & $100 \mathrm{a}$ & $100 \mathrm{a}$ & $4,00 \mathrm{a}$ & $4,00 \mathrm{a}$ & $4,00 \mathrm{a}$ \\
\hline 30 h temp.amb. Água com esporos & $74 \mathrm{~b}$ & $100 \mathrm{a}$ & $100 \mathrm{a}$ & $2,00 \mathrm{~b}$ & $3,62 \mathrm{~b}$ & $3,86 \mathrm{~b}$ \\
\hline $\mathrm{Ca}(\mathrm{OH})_{2} \quad 1,5 \%$ & $0 \mathrm{~d}$ & $24 \mathrm{c}$ & $42,0 \mathrm{c}$ & $0,00 \mathrm{c}$ & $0,27 \mathrm{c}$ & $0,55 \mathrm{c}$ \\
\hline $\mathrm{CaCl}_{2} 1,5 \%$ & $1 \mathrm{~d}$ & $30 \mathrm{c}$ & $37,0 \mathrm{c}$ & $0,00 \mathrm{c}$ & $0,35 \mathrm{c}$ & $0,52 \mathrm{c}$ \\
\hline C V. (\%) & & 10,22 & & & 34,23 & \\
\hline
\end{tabular}

*Tratamentos não seguidos pela mesma letra, na vertical, diferem pelo teste de Tuckey, em nível de 5\%.

** Dias após abertura das câmaras.

podendo ser uma alternativa para resolver o problema de contaminação da água, tendo a vantagem de não ser tóxico para o homem.

Supõe-se que o mecanismo pelo qual o aumento de cálcio no tecido reduz a podridão, seja a manutenção da firmeza de polpa e está relacionado aos íons de cálcio na parede celular (Demarty et al., 1984). A estabilidade desta pode estar relacionada às ligações cooperativas da cadeia de poligalacturonase com íons de Ca (Knee, 1978), tornando-a menos acessível a enzimas que causam a perda de firmeza e a degradação, pelas enzimas produzidas por fungos. Conway et al. (1988) demonstraram que, aumentando o conteúdo de cálcio na parede celular, ocorre uma inibição do amolecimento do tecido causado pela enzima poligalacturonase, produzida por Penicillium expansum.

Frutos imersos em água contendo inóculos de fungos apresentaram $100 \%$ dos ferimentos com incidência de podridão, com exceção do tratamento que, após sofrer ferimentos, ficou 30 horas à temperatura ambiente, em que o percentual foi menor, principalmente no momento da abertura das câmaras. Isto parece evidenciar que houve um processo de cicatrização da lesão durante o período de 30 horas, o que veio a dificultar a penetração do fungo. Segundo Pinilla et al. (1994), em kiwi, a exposição dos frutos recém-colhidos à temperatura ambiente, por um determinado período de tempo, proporciona a cicatrização de ferimentos, formando uma barreira física que impede a penetração de esporos e outras estruturas que causam a podridão.

Nos frutos somente imersos em água, houve menor incidência de podridão em relação à água com inóculos, mostrando a importância da troca periódica da água de lavagem ou a adição de produtos fungicidas. A lavagem com água, mesmo contendo fungicida, não gararante total desinfecção dos frutos, podendo ocorrer contaminação se não houver uma filtragem adequada ou renovação da solução.

\section{CONCLUSÕES}

1 - O uso de cal hidratada (1,5\%) e cloreto de cálcio $(1,5 \%)$ na água de lavagem reduz a incidência de podridões em maçãs cultivares Gala e Fuji durante armazenamento refrigerado.

2 - Na cultivar Gala, a cal é mais eficiente que o cloreto de cálcio no controle de podridões.

3 - Uma exposição dos frutos por um período de 30 horas à temperatura ambiente, antes da lavagem, reduz a incidência de podridões em frutos com ferimentos durante $\mathrm{o}$ armazenamento refrigerado, principalmente na cv. Gala.

4 - A contaminação da água de lavagem com esporos de Penicillium $s p$. aumenta a ocorrência de podridões em maçãs. Temperado, da UFPel. Bolsista do CNPq.

\section{REFERÊNCIAS BIBLIOGRÁFICAS}

BLEICHER, J.; BERNARDI, J. Podridões de maçã e seu controle na pós-colheita. Florianópolis: EMPASC, 1985. 24p. (Boletim técnico, 28).

CONWAY, W.S.; GROSS, K.C.; BOYER, C.D.; SAMS., C.E. Inhibition of Penicillium expansum polygalacturonase activity by increased apple cell wall calcium. Phytopathology, Palo Alto, v.78, p.1052-1055, 1988.

BRACKMANN, A.; MAZARO, S.M.; CECCHINI, R. Préresfriamento e tratamento químico pós-colheita de maçãs cvs. Golden Delicious e Fuji. Ciência Rural, Santa Maria, v.26, n.2, p.185-189,1996.

DEMARTY, M.; MORVAN, C.; THELLIER, M. Calcium and the cell wall. Plant cell environ, New York, v.7, p.441-448, 1984.

KNEE, M. Properties of polygalacturonate and cell cohesion in apple fruit cortical tissue. Phytochemistry, Oxford, v.17, p.12571260, 1978. 
PALADINI, L.A.; EBERT, A. Extração de cálcio da solução de tratamento pós-colheita em maçãs. Revista Brasileira de Fruticultura, Cruz das Almas, v.9, n.1, p.71-75, 1987.

PINILLA, B.C.; ALVAREZ, M.A.; GARCIA, M.A.G. Pudricion peduncular de post-cosecha causada por Botrytis cinerea en kiwi. Revista Fruticola, Santiago do Chile, v.15, n.2, p.63-66, 1994. SANHUEZA, R.M.V. Recomendações para o controle póscolheita das podridões de maçãs. Bento Gonçalves: EMBRAPA-
CNPUV, 1996.4p. (Comunicado técnico, 21).

ZAFFARI, G.R.; EBERT, A.; BASSO, C.; STUKER, H. Aplicação de cloreto de cálcio e cálcio quelatizado em macieiras de cultivar Golden Delicious. Revista Brasileira de Fruticultura, Cruz das Almas, v.11, n.1, p.7-11, 1989 .

WANG, C.Y. Chilling Injury of tropical horticultural commodities. HortScience, Alexandria, v.29 n.9, p.986-988, 1994. 